\title{
Fabricando falsas verdades: la prensa italiana de izquierdas y la construcción de la imagen de palestinos e israelíes (1947-1957)*
}

\author{
Dario MigLiucCI \\ Universidad de Granada \\ dariomigliucci@hotmail.com
}

Recibido: 30/12/2014

Aceptado: 01/06/2015

\begin{abstract}
Resumen
El objetivo del presente estudio es analizar la forma en la que la prensa italiana de izquierdas construyó la imagen de palestinos e israelíes entre 1947 y 1957. La investigación se ha centrado en el estudio de los artículos publicados por algunos destacados periódicos de la época, con la finalidad de comprender cómo ha ido cambiando el lenguaje empleado por dichos órganos de prensa a la hora de referirse a los moradores de la tierra de Palestina. La tesis de este artículo es que dichos periódicos construyeron múltiples y contradictorias representaciones de judíos y palestinos, representaciones que no tenían nada que ver con la realidad de Oriente Medio, sino que obedecían a cuestiones ideológicas de carácter nacional e internacional (relaciones entre los partidos italianos y evolución de las dinámicas de la guerra fría).
\end{abstract}

Palabras claves: Israelíes, Palestinos, Italia, Prensa, Comunismo, Socialismo, Anarquismo, Representaciones culturales.

\section{Fabricating False Truths: the Leftist Italian Press and the Construction of the Israeli and Palestinian Image (1947-1957)}

\begin{abstract}
The aim of this work is to analyze how the leftist Italian press built the Israeli and Palestinian image between 1947 and 1957. The research has been focused on the study of the articles that were published in important periodicals of that period, with the purpose of analyzing the way in which these newspapers and magazines changed the language they used to talk about the inhabitants of the land of Palestine. The thesis of this article is that these periodicals built up multiple and contradictory representations of Israelis and Palestinians. These representations were not related to the Middle East reality. On the contrary, they were due to national and international ideological questions (the relationships among Italian parties and the evolution of the Cold War dynamics).
\end{abstract}

Key words: Israelis, Palestinians, Italy, Press, Communism, Socialism, Anarchism, Cultural representations.

\author{
Abreviaturas \\ PCI (Partido Comunista Italiano) \\ PSI (Partido Socialista Italiano) \\ MAPAI (Partido de los Trabajadores de la Tierra de Israel) \\ E.P. (Edición Piamontés)
}

* Este estudio ha sido realizado gracias a la concesión de una beca de Iniciación a la Investigación del Plan Propio 2013 de la Universidad de Granada. Se agradece al Dr. Miguel Ángel Del Arco Blanco por sus valiosas sugerencias. 
“El 'israelí' y el 'palestino' sólo somos dos actores condenados a subir al escenario, generación tras generación, y representar una grotesca tragedia, cuya última escena nadie consigue escribir". David Grossman ${ }^{1}$

\section{Introducción}

El objetivo del presente trabajo es analizar el proceso de construcción de la imagen de israelíes y palestinos llevado a cabo por la prensa italiana de izquierdas a caballo entre los años 40 y 50 del siglo XX. La investigación se ha centrado en el estudio de los contenidos de los artículos publicados por algunos destacados periódicos italianos de la época, con la finalidad de comprender cómo ha ido cambiando el lenguaje empleado por dichos órganos de prensa a la hora de referirse a los moradores de la tierra de Palestina. En particular, ha sido objeto de estudio la forma en la que estos periódicos contribuyeron -a finales de los años 40- a la creación de algunos grandes mitos del nacionalismo israelí, como el del jardín en el desierto o el de la superioridad moral de los judíos con respecto a los palestinos. Del mismo modo, se ha analizado la forma en la que algunos de estos órganos de prensa posteriormente se volcaron en la destrucción de los discursos que ellos mismos habían contribuido a construir, difundiendo además nuevos mitos -como los complots internacionales sionistas o la creación de Israel como instrumento del imperialismo occidental- con el objetivo de desacreditar al Estado hebraico a ojos de la opinión pública.

Recientemente, numerosos historiadores han abordado el tema del cambio de actitud de la izquierda internacional hacia Israel, un cambio que llevó a la construcción de dos representaciones antagónicas del mismo país, una desmesuradamente positiva y otra extraordinariamente negativa. En 2008 Ronald and Allis Radosh estudiaron el caso de la revista progresista estadounidense The Nation, que en unos pocos años pasó de una versión idealizada de Israel a una demonizada. ${ }^{2}$ Un año más tarde Philip Mendes analizó la actitud filo-sionista de la izquierda australiana durante la guerra civil de Palestina (1947-1948). ${ }^{3}$ En 2013 Mercedes Saborido ha investigado la postura desigual que mantuvo el Partido Comunista de Argentina antes y durante la crisis de Suez. ${ }^{4}$ En 2006 Luca Riccardi ha recordado que en aquellos años el Partito Comunista Italiano pasó rápidamente del entusiasmo con el que acogieron el nacimiento de Israel a una progresiva frialdad hacia el Estado hebraico. ${ }^{5}$ Por su parte, Matteo Di

\footnotetext{
1 GROSSMAN, David: 'Carta a un amigo palestino', El País, 22 octubre 2000

2 RADOSH, Ronald y RADOSH, Allis: "Righteous among the editors: when the Left Loved Israel", World Affairs, Verano 2008, pp.65-75. DOI: 10.3200/WAFS.171.1.65-75

3 MENDES, Philip: 'The Australian Left's Support for the Creation of the State of Israel, 1947-48', Labour History, No. 97 (Nov., 2009), pp.137-148

4 SABORIDO, Mercedes: "De "defensores de una causa santa" a "lacayos del imperialismo". El Partido Comunista de la Argentina y el conflicto de Suez (1956)", Cuadernos de Historia Contemporánea, 2013, vol. 35, pp.193-218. http://dx.doi.org/10.5209/rev_CHCO.2013.v35.42655

5 RICCARDI, Luca: Il problema Israele : diplomazia italiana e PCI di fronte allo Stato ebraico, 1948 1973, Milano, Guerini studio, 2006, p.10
} 
Figlia ha estudiado la relación de amor-odio entre la comunidad judía italiana y los movimientos de izquierdas. ${ }^{6}$

En cuanto al presente trabajo, su objetivo es llevar a cabo un profundo análisis de las representaciones sobre Oriente Medio construidas por la prensa italiana de izquierdas. Se trata de estudiar estas representaciones, no de contrastarlas con la realidad de la Palestina de aquellos años. Tal y como sugirió Peter Burke, el objetivo no debe ser tanto el de oponer la realidad al mito, siendo lo verdaderamente importante la realidad del mito. ${ }^{7}$

La tesis de este trabajo es que dichos órganos de prensa construyeron múltiples y contradictorias representaciones de judíos y palestinos, representaciones que no estaban relacionadas con la realidad material que se estaba viviendo en aquellos años en Oriente Medio, sino que eran consecuencia de cambios de líneas editoriales que obedecían a cuestiones políticas e ideológicas de carácter nacional e internacional.

Para demostrar esta tesis, se han estudiado los contenidos de seis destacados órganos de prensa de la época. En cuanto a la prensa comunista, se han analizado los artículos que fueron publicados en aquellos años por $L$ 'Unità, el diario fundado por Antonio Gramsci, por entonces -bajo la dirección de Pietro Ingrao- el órgano oficial del PCI; el mensual Rinascita, fundado y dirigido desde 1944 por el entonces número uno del partido comunista, Palmiro Togliatti; y el Calendario del Popolo, quincenal difundido por la Sezione Stampa e Propaganda de la dirección del partido comunista. Asimismo, se ha explorado el contenido de los artículos del Avanti!, entonces órgano oficial del Partito Socialista Italiano, el cual mantuvo -hasta 1956- una alianza política con el PCI. Su director, entre 1949 y 1951 -precisamente cuando el diario revolucionó por primera vez su mensaje sobre la situación de Palestina- era el futuro presidente de la República italiana, Sandro Pertini. También han sido objeto de estudio las páginas de Il Libertario, periódico de la Federazione Anarchica Lombarda y de Il Ponte, mensual florentino liberalsocialista fundado y dirigido por el histórico intelectual antifascista Piero Calamandrei. Los diarios L'Unità y Avanti! publicaban ya entonces cientos de miles de copias diarias, mientras que Il Ponte y sobre todo Il Libertario tenían una tirada más limitada. El periódico anárquico salía a la venta semanalmente, con frecuentes interrupciones en sus publicaciones. Rinascita era un semanal ideológico destinado a los militantes más eruditos del PCI, mientras que $\mathrm{Il}$ Calendario del Popolo empleaba un lenguaje divulgativo, lo que lo llevó a alcanzar cierto éxito de difusión. ${ }^{8}$

6 DI FIGLIA, Matteo: Israele e la sinistra : gli ebrei nel dibattito pubblico italiano dal 1945 a oggi, Roma, Donzelli, 2012

7 BURKE, Peter: La Fabricación de Luis XIV, Madrid, Nerea, 1995, p.16

8 MURIALDI, Paolo: La stampa italiana del dopoguerra : dalla liberazione agli anni del centrismo, Roma-Bari, Laterza, 1978, p.102 


\section{Israel como materialización de la utopía socialista y quintaesencia de la lucha antiimperialista}

Los periódicos italianos de izquierdas apoyaron con entusiasmo el nacimiento de Israel, lo que no es de extrañar, pues en aquella época la práctica totalidad de la izquierda internacional respaldaba a los judíos de Palestina. El socialista francés León Blum exigía que se permitiese que los supervivientes de los exterminios hitlerianos alcanzasen el único refugio al que podían "naturalmente aspirar: la tierra de Palestina puesta en cultivo por sus hermanos". "Asimismo, los exiliados de la Segunda República española expresaron reiteradamente su simpatía por el proyecto sionista, escribiendo muchos de los poetas que habían sido desterrados de España copiosos versos en homenaje a la nación hebraica. Rafael Alberti, por ejemplo, compuso el "Salmo de Alegría por la creación del Estado de Israel". ${ }^{10}$ El Kremlin, por su parte, definía al sionismo como un "movimiento de liberación nacional", creyendo además que Israel podía neutralizar la influencia británica en Oriente Medio y convertirse en la cabeza de puente de Moscú en Oriente Próximo. ${ }^{11}$ Con todo, la campaña comunista a favor de Israel fue inicialmente modesta, pues hasta finales de 1947 los soviéticos habían manifestado cierta simpatía también por los enemigos de los judíos. ${ }^{12}$ Todavía en octubre de 1947, L'Unità aseveraba que la partición de Palestina en dos Estados -la solución que los judíos anhelaban y que los palestinos rechazaban- era el proyecto que "más fomentaría un continuo odio entre árabes y judíos, creando un permanente peligro de guerra". ${ }^{13}$ Sin embargo, a partir de noviembre de 1947, es decir, tras el visto bueno de los soviéticos al proyecto, la prensa comunista comenzó a defender la solución de los dos estados. En julio de 1948 Il Calendario del Popolo escribía que la partición de Palestina había sido "la única solución equitativa posible". ${ }^{14}$

La izquierda italiana no albergaba ninguna duda sobre la legitimidad de la presencia de un hogar judío en Tierra Santa. El hecho de que Palestina les perteneciese a los judíos resultaba incuestionable, sobre todo considerando -tal y como escribía Il Libertario- que éstos habían "adquirido y pagado" las tierras que habían ocupado. ${ }^{15}$ L'Unità, por su parte, mostraba indignación cada vez que, en ámbito internacional, se intentaba recortar el territorio israelí, substrayéndole el desierto del Néguev o a través de la internacionalización de Jerusalén. ${ }^{16}$ Il Ponte matizaba que la experiencia

9 Citado en CULLA, Joan B.: La tierra más disputada : el sionismo, Israel y el conflicto de Palestina, Madrid, Alianza, 2005, p.147

10 ISRAEL GARZÓN, Jacobo: El exilio republicano español y los judios : apuntes de literatura, Madrid, Hebraica, 2009, pp.71-79

11 BEN AMI, Shlomo y MEDIN, Tzvi: Historia del Estado de Israel: (génesis, problemas y realizaciones), Madrid, Rialp, D.L., 1992, pp.258-259 p. 138

12 RICCARDI, Luca: Il problema Israele ..., p.43; y MENDES, Philip: ‘The Australian Left's Support...”,

13 L'Unità (E.P.): 'Armi inglesi agli arabi mentre incombe la guerra santa', 12 octubre 1947, p.4

14 Il Calendario del popolo: 'Storia di una speculazione imperialistica su drammi di nazionalità e di razza', julio 1948 , p. 250

15 MONY: 'Palestina...', Il Libertario, 28 enero 1948

16 L'Unità: 'Il riconoscimento di Israele', 28 enero 1949, p.4; y L'Unità: 'Mediazione turca all'O.N.U. per la questione delle ex colonie', 17 abril 1949, p.5 
judía en Oriente Medio no tenía nada que ver con el colonialismo, siendo "una obra excepcional de reconstrucción de una patria para un pueblo entero". ${ }^{17}$

Estos periódicos contribuyeron a construir algunos de los principales mitos del nacionalismo israelí, avalando por ejemplo la teoría de la puesta en cultivo de una tierra vacía, una doctrina según la cual Palestina estaba casi despoblada antes de la llegada de los hebreos, habiendo sido el sionismo el detonante del incremento de la población no-judía. De acuerdo con el Avanti!:

La población árabe de Palestina, poco numerosa y miserable, ha sido estacionaria y decreciente durante siglos. Sin embargo, tras la migración hebraica (...) el número de los árabes se ha doblado en pocos años, y eso pese a que los estados cercanos están poco poblados ${ }^{18}$

También se promovió la idea de que Israel era una isla de libertad en un océano de tiranía. Tal y como se leía en L'Unità, los árabes estaban llevando a cabo una campaña anti-judía ("una cruzada santa bajo la bandera verde del profeta", según el diario comunista) debido a que Gran Bretaña quería "destruir al único estado democrático de Oriente Medio. ${ }^{19}$

Pronto se llegó a la creación de una representación idílica del Estado hebraico, reforzándose sobre todo el mito relativo al maravilloso jardín que los judíos estaban construyendo en el desierto. En 1947 L'Unità atestiguaba que "Tel Aviv, una gran ciudad moderna", había "nacido de la nada". ${ }^{20}$ El mismo diario, en 1948, afirmaba que:

Los judíos en aquel país retrasado llevaron capitales, máquinas, técnicos y culturas modernas. Les compraron a los señores árabes grandes extensiones de tierra, sobre todo destinadas al pasto, las transformaron en tierras cultivables utilizando tractores y abonos químicos hasta entonces desconocidos, las regaron, fundaron fincas, aldeas, cooperativas, escuelas, hospitales, desarrollaron industrias. ${ }^{21}$

En diciembre de 1947 el Avanti! aseveraba que los judíos habían "llevado las costumbres del vivir moderno" a una tierra que durante siglos había conocido "la primitiva dominación de los turcos". ${ }^{22} \mathrm{Y}$, si comunistas y socialistas exaltaban el triunfo de la modernidad hebraica frente a las primitivas culturas islámicas, los anarquistas forjaban una visión más romántica de la experiencia judía, en la que la lucha antiimperialista se entrelazaba con un saludable retorno a la naturaleza y al trabajo manual:

Nosotros tomamos decididamente partido por (...) los colectivistas judíos, por todas aquellas jóvenes y heroicas generaciones de pioneros de una nueva civilización

17 NIERENSZTEIN, Alberto: 'Aspetti della politica interna in Palestina', Il Ponte, julio 1948, p.712

18 CHAPMAN, Burgoyne B.: 'Arabi ed ebrei nello Stato d'Israele', Avanti!, 10 julio 1949, p.6

19 SEGRE, Sergio: 'La popolazione di due villaggi ebraici è stata massacrata da truppe egiziane', L'Unità (E.P.), 16 mayo 1948

20 L'Unità (E.P.): 'L'arabo biondo', 27 julio 1947, p.3

21 PASTORE, Ottavio: 'Guerra in Palestina', L'Unità (E.P.), 23 mayo 1948

22 BORGONI, Antonio: 'Terra Santa', Avanti!', 19 diciembre 1947 
del trabajo que -poetas, ingenieros, médicos, intelectuales- no menosprecian empuñar una pala, conducir un arado, manejar los ladrillos para edificar aquellas maravillosas colectividades agrícolas e industriales que desde hace sesenta años están trasformando las pedregosas tierras palestinas en oasis de progreso fecundo. ${ }^{23}$

El foco de este progreso eran las comunidades agrícolas Kibutz, representadas como paraísos terrenales rebosantes de bienestar y justicia social. Il Libertario relataba que allí no existían ni privilegios, ni dinero, ni propiedad privada, ni jefes. ${ }^{24} \mathrm{El}$ Avanti! destacaba además la diferencia entre los resplandecientes Kibutz y las miserables tierras de los otros habitantes de Palestina:

Aparecen como oasis en el desierto. Realmente han transformado el paisaje palestino: aparecen así de aisladas y tan en contraste con la desolación circundante que parece que sean lo único que ha quedado en pie tras un desastre que lo ha devastado todo. ${ }^{25}$

Para estos periódicos Israel era el ejemplo fehaciente de que sus atrevidos sueños políticos podían materializarse, representándose además al pueblo hebraico como la quintaesencia de la doctrina socialista. Según Il libertario, los Kibutz eran la prueba de que el colectivismo no era "una utopía propugnada por exaltados, sino una realidad histórica". ${ }^{26}$ El Avanti! dejaba incluso entender que Marx pudo ser Marx precisamente porque era de origen judío, pues "en él subsistían ciertamente los recuerdos tradicionales, grabados en su alma, de las disposiciones jurídicas socialistas de la antigua sociedad hebraica". ${ }^{27}$ El pueblo hebraico, además, era representando como una reencarnación de gloriosas experiencias del pasado como la Segunda República española y la revolución bolchevique. ${ }^{28}$

Un papel fundamental se asignaba al ejército hebraico, que L'Unità definía como "un organismo políticamente muy elevado". ${ }^{29}$ En mayo de 1948, con el fin de destacar la heroica resistencia de los soldados israelíes ante las embestidas de las tropas islámicas, se llegó a definir Jerusalén como la "Stalingrado hebraica", lo que no sólo asociaba a los israelíes con el legendario ejército rojo, sino que acababa comparando a la Liga árabe con las tropas nazis. ${ }^{30} \mathrm{El}$ día después el mismo diario afirmaba que en el campo de batalla había una "superioridad hebraica tanto táctica como moral". 31 Una idea que se trasmitía incesantemente era que se trataba de un ejército de civiles, parecido a aquellas tropas voluntarias -muy populares entre los lectores de izquierdas de la época- que pocos años antes habían luchado en la resistenza antifascista. El Avanti! informaba que "un profesor de filosofía, amante de la pesca", había sido nom-

23 MANTOVANI, Mario: 'Noi scegliamo il popolo di Palestina', Il Libertario, 26 mayo 1948

24 MANTOVANI, Mario: 'Difesa del socialismo in Palestina', Il Libertario, 9 junio 1948; y VELLA, Giuseppe: 'Colonie ebraiche in Palestina', Il Libertario, 4 enero 1950, p.2

25 ASCOLI, A.: 'Il destino della terra è nascosto nei Kibbuz', Avanti!, 17 julio 1948

26 VELLA, Giuseppe: 'Colonie ebraiche in Palestina...'

27 ASCOLI, A.: 'Il destino della terra...'

28 MANTOVANI, Mario: 'Noi scegliamo...' ; y MANTOVANI, Mario: 'Difesa del socialismo...'

29 KARTOUN, Derek: 'La guerra continua in Palestina', L'Unità, 3 junio 1948

30 M.U.: 'L'Inghilterra impedisce all'O.N.U. la soluzione del conflitto palestinese', L'Unità (E.P.), 21 mayo 1948

31 KARTOUN, Derek: 'Ho visto combattere l'esercito d'Israele', L'Unità (E.P.), 22 mayo 1948 
brado comandante de la flota. ${ }^{32}$ Trascendental fue también el rol que se les hizo jugar a las mujeres-soldado, las cuales transmitían la idea de que no se estaba lanzando una guerra de conquista, sino que se estaban defendiendo hogares y familias de las embestidas de agresores ajenos a aquellas tierras. L'Unità consideraba imprescindible destacar que era "una rubia" quien acaudillaba a las unidades de asalto. ${ }^{33} \mathrm{El}$ Avanti! aseguraba que las mujeres no eran inferiores a los hombres en cuanto a "espíritu de aventura, combatividad y fantasía". ${ }^{34}$ Il Libertario añadía que, "como ya las heroicas milicianas de la revolución de España", la mujer israelí empuñaba el rifle y excavaba trincheras "para defender a su comunidad y a su hogar". ${ }^{35}$

Pese a esta constante glorificación de las milicias hebraicas, también se forjaba la imagen de un Israel pacífico. Comentando el estallido de la primera guerra árabeisraelí, L'Unitá aseguraba que el Estado hebraico se había visto "obligado a empuñar las armas contra las naciones árabes y a defender sus fronteras". ${ }^{36}$ Il Libertario opinaba que los trabajadores occidentales debían respaldar a Israel, "para que su mano tendida al humilde felah árabe no fuese rechazada". ${ }^{37} \mathrm{Y}$, sobre todo, se pretendía destacar que, pese a su superioridad técnica, los judíos seguían siendo la parte débil. El Avanti! se preguntaba si los judíos:

¿No se están preparando un triste destino, pequeño núcleo rodeado por setenta millones de árabes que vuelven a entrar en la historia con renovada voluntad de potencia? ${ }^{38}$

En suma, estos periódicos construyeron un tipo ideal de israelí que empujaba a los lectores a simpatizar con la causa sionista. El pueblo hebraico era descrito como la quintaesencia del colectivismo, siendo una comunidad pacífica que, paradójicamente, también destacaba por su lucha anti-imperialista.

\section{El palestino: imprescindible enemigo del buen israelí}

La construcción de esta paradisíaca representación de Israel tuvo que pasar inevitablemente por la denigración de los palestinos. Todo arquetipo positivo sobre la comunidad hebraica estuvo estrechamente ligado a un estereotipo negativo sobre la sociedad islámica. Si la noción "judío trabajador" se asociaba asiduamente al concepto "árabe incapaz", la alusión al "israelí pacífico" se vinculaba constantemente a la idea del "árabe agresor". Así resumía el Avanti! "25 años de dura lucha entre árabes y judíos":

\footnotetext{
32 POLIDORI, G.L.: 'Così è nato l'esercito d'Israele', Avanti!, 30 enero 1949, p.5

33 KARTOUN, Derek: 'Ho visto combattere l'esercito d'Israele...'

34 POLIDORI, G.L.: 'Così è nato l'esercito d'Israele...'

35 MANTOVANI, Mario: 'Noi scegliamo...'

36 SEGRE, Sergio: 'La popolazione di due villaggi ebraici...'

37 MANTOVANI, Mario: 'Difesa del socialismo...'

38 BORGONI, Antonio: 'Terra Santa' ...
} 
La conciencia de los árabes se ha formado con una pasión nacional exacerbada por el fanatismo religioso. El sueño hebraico es la tierra prometida, la tierra de los padres, la liberación de la secular esclavitud de vivir como extranjeros entre otros pueblos. ${ }^{39}$

Un concepto clave de la campaña de descrédito contra los enemigos de Israel era el relativo a su innata cobardía. Il Libertario juzgaba "insuficientes" las fuerzas de la Liga árabe debido a su "escasa combatividad". ${ }^{40}$ El Avanti! escribía que "los árabes huían tan rápido" que los judíos se habían convencido de que ganar batallas era "lo más fácil del mundo". ${ }^{41}$

En octubre de 1947 L'Unità tachó a la Liga árabe de "oscura potencia". ${ }^{42}$ En diciembre el mismo diario la definió como "el máximo órgano de la feudalidad árabe", representante de "los intereses de pequeños monarcas, 'ras' y grandes propietarios de tierras". ${ }^{43}$ Por su parte, Il Calendario del popolo aseguraba que las naciones islámicas tenían "una fisionomía reaccionaria de las más atrasadas", tratándose de "pequeños reinos despóticos o gobernados por pequeñas castas". ${ }^{44}$ En 1949 L'Unità quisó destacar la diferencia entre "los estados árabes reaccionarios" e Israel, "país abierto a toda idea progresista". ${ }^{45}$

Los pueblos autóctonos eran vistos como unos párvulos que deberían haber estado agradecidos por la llegada de los maestros judíos. Il Calendario del popolo escribía que los judíos estaban llevando a cabo una "intensa actividad civilizadora" en Oriente Medio. ${ }^{46}$ De acuerdo con L'Unità, la sociedad hebraica era “más evolucionada, más moderna que la árabe", de ahí que la presencia judía "elevase el nivel de vida del proletariado árabe". El diario añadía que los palestinos tendrían tiempo para "preguntarles a los judíos el secreto que les permite conquistar palmo a palmo el desierto". ${ }^{47}$ Il Libertario afirmaba que los palestinos sólo podían "ganar con el nacimiento de un gran conglomerado hebraico, pues los judíos llevaron industrias, comercios y mejoras de la tierra que los árabes jamás pudieron soñar". ${ }^{48}$

Además, si a los judíos se les pintaba como víctimas, a los islámicos se les debía inevitablemente tachar de agresores, y -aunque resulte paradójico- incluso de "cruzados". 49 Se publicaban crónicas que sólo relataban las atrocidades contra los hebreos. El 15 de mayo de 1948 L'Unità acusaba a los "feroces guerreros árabes" de "asesinar a los prisioneros". ${ }^{50} \mathrm{Al}$ día siguiente, se refería que la población de dos aldeas hebraicas había sido masacrada por los egipcios, quienes se habían "manchado

39 Ibidem.

40 MANTOVANI, Mario: 'Noi scegliamo...'

41 POLIDORI, G.L.: 'Così è nato l'esercito d'Israele...'

42 L'Unità (E.P.): 'Gli stati arabi in armi mobilitano ai confini della Palestina', 11 octubre 1947, p.4

43 L'Unità (E.P.): 'La Lega araba decisa a proclamare la guerra santa', 9 diciembre 1947, p.4

44 Il Calendario del popolo: 'Storia di una speculazione...'

45 DE CUGIS, Carlo: 'L'Inghilterra arma gli Stati arabi”, L'Unità (E.P.), 4 enero 1949, p.4

46 Il Calendario del popolo: 'Storia di una speculazione...'

47 PASTORE, Ottavio: 'Guerra in Palestina ...'; y L'Unità, 'L'arabo biondo' ...

48 MONY: 'Palestina...' ...

49 Avanti!: 'Lo stato d'Israele riconosciuto dall'America e dall'unione Sovietica', 15 mayo 1948; y SEGRE, Sergio: 'La popolazione di due villaggi ebraici...'

50 L'Unità: 'L'Egitto in guerra con lo Stato d'Israele. La Palestina invasa su un fronte di $50 \mathrm{~km}$ ', 15 mayo 
de crímenes atroces". ${ }^{51}$ El 20 de mayo se denunciaba un bombardeo que había acabado con la vida "de muchas mujeres y niños". ${ }^{52}$ Una semana más tarde Il Libertario escribía que la Liga árabe había "salvajemente bombardeado los centros habitados y llevado destrucción y muerte a las comunidades agrícolas" de Israel. ${ }^{53}$ El 26 de mayo L'Unità manifestaba horror por el hecho de que quinientos judíos habían sido degollados. ${ }^{54}$ Aquel mismo día el Avanti! aseguraba que Jerusalén había sido víctima del primer ataque aéreo de su historia, "algo que ni siquiera Hitler había osado", y que "bandas de beduinos" afluían a la ciudad "para participar en la matanza". ${ }^{55}$ El 1 de junio se anunciaba que los enemigos de Israel estaban a punto de "utilizar gases" contra Tel Aviv. ${ }^{56}$ En estas crónicas los árabes eran un colectivo sediento de sangre, incapaz de experimentar empatía, que llevaba a cabo brutalidades sin razón alguna. El 3 de julio el Avanti! relataba que los soldados islámicos se divertían "prendiéndole fuego con sus morteros a las plantaciones hebraicas". Los judíos, además, no eran las únicas víctimas de sus crueldades, pues los árabes atacaban también a los convoyes de la ONU". ${ }^{57}$ También se relataban las bárbaras condiciones a las que los soldados árabes se veían sometidos por sus superiores. L'Unità denunciaba el hallazgo de cadáveres de iraquíes que habían sido atados entre sí de dos en dos "para impedirles abandonar su puesto". 58

Y, si Israel venía constantemente comparado a los republicanos españoles, a los árabes se les solía comparar con los nazis. L'Unità informaba que:

Irak ha adoptado hoy severas medidas en contra de judíos y comunistas. Todas las personas que pertenecen a estas dos categorías serán internadas en campos de concentración: los métodos de la Alemania nazi vuelven así en vigor en los estados protegidos por los angloamericanos. ${ }^{59}$

Una prioridad era señalar la presencia de ex soldados nazis entre los enemigos de Israel. El Avanti! documentaba la presencia en la Liga árabe de dos pilotos "que ya estuvieron al servicio de la Lutwaffe de Goering". ${ }^{60}$ L'Unità reportaba que habían sido capturados militares alemanes, entre los cuales se hallaba el ex coronel de las S.S. Eichenau. ${ }^{61}$ El órgano del PCI también informaba de que un ex oficial de la Luftwaffe había reclutado a veteranos nazis para enviarlos a Palestina, constituyendo "una especie de legión extranjera anti-semita". ${ }^{62}$

\footnotetext{
51 SEGRE, Sergio: 'La popolazione di due villaggi ebraici ...'

52 L'Unità: 'Vergognoso sabotaggio inglese all'intervento dell'ONU in Palestina', 20 mayo 1948

53 MANTOVANI, Mario: 'Noi scegliamo...'

54 M.U.: 'Gli arabi per cessare il fuoco chiedono la resa incondizionata d'Israele', L'Unità (E.P.), 16

55 Avanti!: 'Primo attacco aereo contro la Città Santa', 26 mayo 1948

56 L'Unità: 'Gli arabi investono Tel Aviv e si preparano ad usare i gas', 1 junio 1948

57 L'Unità: 'Attentato in Palestina a un convoglio dell'ONU', 23 septiembre 1948, p.4

58 L'Unità: 'Lo sciopero della fame iniziato dagli ebrei internati a Cipro', 8 junio 1948, p.4

59 M.U.: 'Giaffa si è arresa alle forze dell'Haganah', L'Unità (E.P.), 14 mayo 1948, p.4

60 Avanti!: 'Bombardata da un aereo la città araba di Giaffa?', 30 marzo 1948, p.4

61 SALVIATI, Corrado: 'La Transgiordania invade la Palestina col consenso degli angloamericani', L'Unità (E.P.), 24 abril 1948

62 L'Unità: 'Il partito nazista ricostituito negli istituti religiosi teutonici', 4 septiembre 1949, p.2
} mayo 1948 
A la hora de analizar la postura de estos periódicos, no sólo son importantes sus tomas de posición, sino que resultan igualmente fundamentales sus deliberados silencios. Ninguno de estos órganos de prensa destacó el sufrimiento de las víctimas nojudías. Las bajas de la Liga árabe apenas se mencionaban, siendo aún más raras las referencias a víctimas civiles. Además, sólo raramente se mencionaba la deportación de la población palestina, y en todo caso sólo para negar que Israel tuviese responsabilidades. ${ }^{63} \mathrm{El}$ Avanti! aseguraba que habían sido los palestinos quienes habían decidido evacuar sus tierras, eso para "desacreditar a los judíos, haciendo que pareciesen los despiadados persecutores de los musulmanes". ${ }^{64}$ En otro artículo el mismo periódico afirmaba que los enemigos de Israel habían ordenado a los palestinos abandonar sus tierras porque pensaban que, sin población musulmana, hubiese sido más fácil "destruir Israel y masacrar a los judíos". ${ }^{65}$ Los prófugos eran tachados de traidores, y se defendía que ya no tenían derecho a volver a sus hogares:

Cómo se puede pedir a un estado que vuelva a acoger dentro de sus fronteras, a poblaciones que han mostrado no tener lealtad, estando (si bien por miedo) a las órdenes de enemigos externos (...). ${ }^{66}$

Cabe preguntarse cuáles eran, según estos periódicos, las verdaderas causas del conflicto. El Avanti! hablaba de los celos de los musulmanes, los cuales habían visto "con envidia la prosperidad de las explotaciones de los recién llegados" ${ }^{67}$ Según Rinascita las guerras contra Israel permitían que las poblaciones de la región olvidasen a sus verdaderos opresores. ${ }^{68}$ L'Unità afirmaba que la Liga árabe estaba "intentando suscitar una oleada nacionalista y racista", y que los partidos reaccionarios y las altas jerarquías musulmanas estaban buscando "la unidad de los árabes en la lucha contra el sionismo con el fin de distraer su atención de la lucha contra el feudalismo y el imperialismo extranjero" ${ }^{69}$. El mismo periódico, comentando el asesinato, por parte de terroristas judíos, del mediador de la ONU, Folke Bernadotte, añadía:

Tanto Bernadotte como aquéllos que lo habían enviado habían olvidado que esta guerra era abiertamente y sin lugar a equivocaciones una guerra de agresión contra Israel, un estado nacido conforme a una decisión de la ONU, por parte de estados árabes de Oriente Medio, o más exactamente por parte de los jefes feudales de estos países que, al servicio de los imperialistas británicos, buscan en la lucha contra los judíos desviar la lucha de liberación de los pueblos árabes. Extraña mediación, pues, la que se le confió a Bernadotte: mediación entre agresor y agredido. ${ }^{70}$

\footnotetext{
63 PAPPÉ, Ilan: La Limpieza étnica de Palestina, Barcelona, Crítica, 2008

64 Avanti!: 'Gli inglesi sono partiti. A chi gioverebbe la vittoria araba?', 19 mayo 1948, p.3

65 CHAPMAN, Burgoyne B.: 'Arabi ed ebrei nello Stato ..."

66 Ibidem.

67 Avanti!: 'L'immigrazione ebraica', 19 mayo 1948, p.3

68 SEGRE, Sergio: 'Le contraddizioni internazionali del fronte imperialista e la lotta dei popoli coloniali', Rinascita, agosto 1948, p.321

69 MEADE, John: 'Scoperta una strana storia di franchi tiratori "indipendenti", 25 diciembre 1947, L'Unità (E.P.), p.4

70 GER: 'La morte di Bernadotte', 19 septiembre 1948, L’Unità (E.P.), p. 4
} 
El conflicto de Palestina era además descrito como una guerra por el petróleo, eso también debido a que el oro negro, según aseguraba el Avanti!, estaba a punto de agotarse. ${ }^{71} L$ 'Unità opinaba que la agresión contra Israel se debía a "una casta de petroleros norteamericanos", los cuales habían permitido la trasformación de Palestina en un campo de batalla en el que "los árabes, armados por los ingleses, tenían derecho de vida y muerte sobre los judíos". ${ }^{72}$ El diario también refería que los británicos pretendían controlar la región debido al descubrimiento de un yacimiento de uranio en el Néguev. ${ }^{73}$ Rinascita, además, señalaba como causa de las tensiones las preocupaciones británicas por el Canal de Suez. ${ }^{74}$ También se destacaba que el imperialismo consideraba que Israel era un mal ejemplo para las poblaciones locales. Al siguente día del nacimiento del Estado hebraico, L'Unità explicaba así las razones del estallido de la primera guerra árabe-israelí:

[Israel es] un estado mucho más desarrollado que los coloniales (...) la constitución de un Estado hebraico desarrollado económica y políticamente refuerza las fuerzas democráticas populares en todos los países árabes limítrofes. ${ }^{75}$

Según el diario comunista la formación de un hogar hebraico era un "ejemplo para los países árabes en condiciones semifeudales", algo que los colonialistas "no podía tolerar". ${ }^{76}$ De acuerdo con L'Unità, la introducción en Oriente Medio de un Estado con notable capacidad de desarrollo industrial y comercial constituía "un peligroso elemento de ruptura en la estructura medieval de los países árabes", conviertiéndose en "una espina en el corazón para los intereses estratégicos ingleses". ${ }^{77}$

\section{Una repentina inversión de roles: una parte de la prensa de izquierdas modifica su línea editorial}

A partir de finales de 1949 una parte de la prensa italiana de izquierdas experimentó un cambio repentino de línea editorial. En un lapso de tiempo extremadamente breve, algunos de estos órganos de comunicación pasaron de una visión idealizada del Estado hebraico a una demonizada, transformando a los palestinos de agresores a víctimas. Esta nueva política estuvo sin duda ligada a un cambio de actitud decidido en el seno de PCI y PSI, lo que a su vez fue consecuencia del empeoramiento de las relaciones entre Unión Soviética e Israel. El gobierno ruso, en efecto, había apoyado a Israel durante los primeros dos años de su existencia, distanciándose del Estado hebraico a finales de 1949. En diciembre de aquel año Moscú se expresó a favor de

\footnotetext{
71 Avanti!: ‘Addio petrolio fra vent'anni', 6 abril 1947

72 SALVINI, Cesare: 'I banchieri del petrolio dirigono la politica americana in Palestina', L'Unità (E.P.), 21 abril 1948, p.4

73 DE CUGIS, Carlo: 'Israele chiede la convocazione del Consiglio di Sicurezza', L'Unità (E.P.), 12 enero 1949, p.4

74 Rinascita: 'Quadrante Internazionale', marzo 1949, p.102

75 SEGRE, Sergio: 'La popolazione di due villaggi ebraici...'

76 PASTORE, Ottavio: 'Guerra in Palestina...'

77 L'Unità: 'Il riconoscimento di Israele'...
} 
la internacionalización de Jerusalén. De todas formas, se trató de un proceso bidireccional. Israel al principio se había mantenido fiel a una política de equidistancia con los dos bloques de la guerra fría, apostando desde 1950 por una alianza más clara con occidente. De acuerdo con el historiador Uri Bialer, podemos indicar como punto de ruptura la decisión, por parte de la delegación israelí en la ONU, de votar de acuerdo con las pretensiones norteamericanas en ocasión de la crisis coreana. ${ }^{78}$

A partir de este momento una parte importante de los periódicos que se han analizado en este trabajo alteró completamente sus discursos, pasando de la dicotomía judíos buenos/palestinos agresores a la dicotomía israelies malos/palestinos víctimas. Tal y como afirmó el ex director del American Jewish Congress, Henry Siegman, "la noble lucha de liberación nacional de los judíos fue transformada en una aventura colonial". ${ }^{79}$ La prensa de PCI y PSI abandonó la leyenda rosa y comenzó a fabricar la leyenda negra. Viejos falsos mitos como el de la tierra vacía fueron desmontados, y nuevas leyendas comenzaron a ser construidas.

Objetivo prioritario de la nueva campaña fue anular toda asociación entre la imagen de Israel y la idea de jardín en el desierto. Ya en noviembre de 1949 el Avanti! describía al Estado hebraico como una nación pauperizada, que sobrevivía gracias a la ayuda estadounidense. ${ }^{80}$ Desmintiendo la información que se había proporcionado hasta entonces, en mayo de 1950 L'Unità aseveraba que los kibutz no representaban ningún avance, siendo en realidad todo un retroceso:

Uno de los más grandes alardes de la organización sionista es lograr transformar admirablemente en campesinos a un gran número de ingenieros, arquitectos, médicos, profesores y así sucesivamente. Singular alarde para gente que en todo momento dice estar caminando a grandes pasos hacia un país moderno y civil ${ }^{81}$

Entre 1949 y 1950 Israel dejó de ser representado como el paraíso terrenal, comenzando a ser descrito como una nación de fanáticos. En noviembre de 1949 el Avanti! afirmaba que la Universidad de Jerusalén no tenía la Facultad de Medicina porque la disección de cadáveres estaba prohibida, que en los cuarteles a los reclutas ortodoxos no se les podía cortar el pelo, y que se estaba resucitando el hebreo, "una lengua que murió hace 3000 años". ${ }^{82}$

Se comenzó a redactar una nueva versión de la historia en la que Israel ya no representaba la quintaesencia del socialismo, sino que se encontraba a sus antípodas. Según L'Unità Israel era ahora "un estado capitalista, con un modo de producción capitalista $\mathrm{y}$, consecuentemente, con un método capitalista de distribución de los productos". 83 Se mostraba además indignación por el hecho de que quioscos y librerías de Tel Aviv estaban "llenos de publicaciones americanas de la peor especie", siendo también "de

78 BIALER, Uri: Between East and West: Israel's foreign policy orientation 1948-1956, Cambridge, Cambridge University Press, 1990, pp.1-2 y 142

79 Citado en RADOSH, Ronald y RADOSH, Allis.: 'Righteous among the editors...', p.66

80 CARRA, Giorgio: 'Quasi mille persone al giorno arrivano nella "terra promessa"”, Avanti!, 10 noviembre 1949, p.4

81 JACOVIELLO, Alberto: 'Come vive la gioventù nei “kiboutzy” israeliti', L'Unità, 16 mayo 1950, p.3

82 CARRA, Giorgio: 'Proibito tagliare i capelli alle reclute', Avanti!, 23 noviembre 1949, p.3

83 JACOVIELLO, Alberto: 'Come vive...' 
inspiración americana la mayoría de los carteles de publicidad. ${ }^{84}$ En otro artículo, se afirmaba incluso que los judíos no habían construido el comunismo, sino "un régimen de libertad sexual que haría feliz a los discípulos de Léon Blum". ${ }^{85}$

Se recuperaban viejos estereotipos que tenían connotaciones antisemitas, como el del judío dueño de las finanzas mundiales o del mundo hebraico organizador de complots internacionales. ${ }^{86}$ El Avanti!, en noviembre de 1949, recordaba "la posición dominante" de la comunidad hebraica en la economía estadounidense, manteniendo algunos judíos "el casi monopolio de las industrias de la confección, pieles, cine y radio". ${ }^{87}$ Se trataba de unas observaciones asombrosas, pues nada similar se había publicado hasta entonces.

Además, en las crónicas publicadas desde 1950 por estos periódicos, desaparecieron las víctimas hebraicas, las únicas que habían aparecido hasta entonces, y comenzaron a aflorar las crueldades perpetradas por los judíos. Ya en mayo de 1950 L'Unità relataba que los palestinos vivían "en condiciones de gran inferioridad con respecto al resto de la población", y que no se les permitía "moverse libremente de una aldea a otra, necesitando una autorización especial de la autoridad militar" ${ }^{88}$ Unos días después el mismo periódico refería que:

Los árabes son una minoría oprimida. Cuando viven en aldeas árabes son gobernados con leyes militares y cuando viven en ciudades con mayoría hebraica se les encierra en una especie de guetos. No tienen derecho a entrar en la Confederación del Trabajo (...) ningún partido sionista los admite entre sus filas y los salarios de los trabajadores árabes son la mitad que los de los trabajadores judíos (...) El partido comunista es el único que lucha contra la política racista del sionismo" ${ }^{89}$

Lo sorprendente es que entre 1949 y 1950 nada cambió en Israel en cuanto a la forma en la que se trataba a la minoría árabe o en cuanto a las relaciones con sus vecinos. Lo que sí había cambiado eran las relaciones entre gobierno israelí y Kremlin.

La campaña anti-israelí de estos periódicos no fue disminuyendo durante los años siguientes. En marzo de 1952, por ejemplo, Il Calendario del Popolo afirmaba que el sionismo se sustentaba:

en el mismo prejuicio racial que era y es propio de los enemigos de los judíos. Los antisemitas (...) han fantaseado sobre un 'misticismo de la sangre' que uniría a los judíos de todo el mundo (véase por ejemplo el 'Mein Kampf' de Hitler). Pues bien, esta curiosa teoría de la compactibilidad mística del 'pueblo hebraico' estaba también en la base de la configuración sionista ${ }^{90}$

84 JACOVIELLO, Alberto: 'In Palestina approdano le nazionalità di tutto il mondo', L'Unità, 11 mayo 1950, p.3

85 JACOVIELLO Alberto: 'Come vive...'

86 Más sobre el "nuevo antisemitismo" en TAGUIEFF, Pierre-André: La Nueva judeofobia, Barcelona, Gedisa, 2003

87 CARRA, Giorgio: 'Proibito tagliare...'

88 JACOVIELLO Alberto: 'In Palestina approdano ...'

89 JACOVIELLO, Alberto: 'Nazareth in Galilea: fortezza rossa d'Israele', L'Unità, 14 mayo 1950, p.3

90 F.F.: 'Il “dalli al giudeo!’ attraverso i tempi', Il calendario del Popolo, marzo 1952, p.1369 
El sionismo ya no se presentaba como un movimiento de liberación, sino como una organización cuya finalidad era "distraer a los judíos de la lucha para emancipar a la sociedad", la misma acusación que se había reservado hasta entonces para la élite islámica. ${ }^{91}$

Huelga decir que a los hebreos ya no se les relacionaba con los republicanos españoles, sino con los enemigos del comunismo soviético, como la Yugoslavia de Tito. ${ }^{92}$

La actitud anti-israelí empeoró cuando en Europa oriental y en Rusia se desencadenaron unas purgas con fuertes matices antisemitas. Al Estado hebraico se le atribuyó un papel trascendental en la supuesta conspiración que fue denunciada en el tristemente célebre juicio de Praga, un proceso en el que varios dirigentes checoslovacos (muchos judíos) fueron acusados de traición. Los comunistas italianos no tardaron en sumarse a estas acusaciones. De acuerdo con Rinascita, el complot había sido obra de "agentes de la embajada de Israel y de miembros del movimiento sionista checo". ${ }^{93}$ L'Unità mantuvo al día a sus lectores del desarrollo del proceso con mucha perseverancia. El 25 de noviembre de 1952 refería que:

Otto Fischl, agente de la Gestapo, colaboró en la eliminación de judíos checoslovacos para convertirse a continuación en un dirigente del movimiento sionista (...) ofreció a elementos capitalistas de origen hebraico la posibilidad de robar gravemente al estado a través de la exportación clandestina a Israel de miles de millones de coronas. ${ }^{94}$

Dos días más tarde el mismo diario insinuaba que durante la guerra había tenido lugar en Washington una reunión entre el presidente estadounidense Harry S. Truman y los futuros dirigentes de Israel, un encuentro durante el cual se acordó un préstamo al Estado hebraico a cambio de que las organizaciones sionistas del este de Europa se pusiesen al servicio del espionaje norteamericano. ${ }^{95}$ En enero de 1953 L'Unità llegaba a afirmar que "todo el sionismo, con sus ramificaciones mundiales, con su naturaleza y su influencia cosmopolita y su potencia financiera" se había aliado, "en la lucha entre los dos campos que dividen el mundo, con el imperialismo estadounidense". ${ }^{96}$ La prensa comunista también afirmó que los médicos judíos detenidos en Rusia en 1953 -acusados de un inverosímil complot para asesinar a dirigentes de la Unión Soviética- eran "criminales al servicio de las organizaciones de espionaje sionistas". ${ }^{97}$ Según escribía Rinascita:

En la vieja organización sionista se habían refugiado y desarrollaban sus actividades provocadoras viejos trotskistas judíos (...) no extraña por tanto el hecho de que médicos judíos ligados a centros de espionaje y provocación también en Moscú hayan deliberadamente intentado suprimir a dirigentes y personalidades soviéticas. ${ }^{98}$

\footnotetext{
91 PROVEDONI, Bruto: 'Il nazionalismo borghese persecutore degli ebrei', Avanti!, 10 febrero 1953

92 PROVEDONI, Bruto: 'Il controllo americano sullo stato d'Israele', Avanti!, 21 febrero 1953, p.3

93 Rinascita: 'Democrazie popolari', noviembre 1952, p.644

94 PASTORE, Ottavio: 'Perché Rudolf Slansky ha tradito il suo Paese', L'Unità, 25 noviembre 1952

95 PASTORE, Ottavio: 'La pena di morte chiesta dal P.M.', L'Unità, 27 noviembre 1952

96 L'Unità: 'Le organizzazioni sionistiche al servizio degli Stati Uniti', 23 enero 1953, p.3

97 L'Unità: 'Il governo di Israele attaccato in Parlamento', 17 febrero 1953, p.6

98 D'ONOFRIO, E.: 'Congiure e delitti contro il socialismo', Rinascita, enero 1953
} 
La prensa comunista se mostró además indignada por el atentado contra la embajada rusa en Tel Aviv que en 1953 provocó la interrupción de las relaciones diplomáticas entre URSS e Israel. L'Unità acusó a Israel de "alimentar sistemáticamente el odio y la enemistad contra la Unión Soviética". ${ }^{99}$

Lo curioso es que estos acontecimientos -la crisis URSS-Israel, el juicio de Praga, o el complot de los médicos- no tenían nada que ver con las divergencias entre israelíes y palestinos, y sin embargo influyeron tajantemente en la forma en la que estos periódicos cubrían el conflicto. En 1955 L'Unità publicaba un editorial titulado “¿Quién es el agresor?”, en el que se leía que "los círculos reaccionarios de Israel" mantenían abierta "la perspectiva de un expansionismo sionista". ${ }^{100}$ También se acabó con el mito de la tierra vacía. Los datos demográficos que proporcionaba ahora L'Unità hablaban más bien de un robo de tierra:

Cuando estalló el conflicto, la tierra de Palestina estaba poblada por 600 mil judíos y 1.100 .000 árabes. En 1950, la población del estado de Israel -que se extiende en el $80 \%$ del territorio de la vieja Palestina- era de 1.200 .000 judíos y 170.000 árabes. ${ }^{101}$

En suma, ya no se aludía a que la población palestina había crecido gracias a los asentamientos judíos. De acuerdo con esta nueva reconstrucción, los judíos no estaban haciendo prosperar la región, sino que estaban echando a perder lo que los árabes habían realizado hasta entonces. En 1955 L'Unità denunciaba que el "masivo éxodo de la población árabe" y la "destrucción de su economía" habían "sacudido profundamente" los equilibrios agrícolas, con el abandono del 70\% de las plantaciones de olivo y con una producción de grano que en 1955 era inferior a la de 1942. ${ }^{102}$

La historia del nacimiento de Israel fue reescrita de arriba a abajo. Il Calendario del Popolo atestiguó que "fueron los Estados Unidos que apostaron con mayor firmeza por el nacimiento de Israel", mientras que la Unión Soviética había patrocinado siempre "la formación de un estado independiente y democrático árabe-israelí". ${ }^{103}$ Es decir, todo lo contrario de lo que la prensa comunista había sostenido hasta finales de 1949.

Israel era representando cada vez más como un país fundamentalista. L'Unità relataba la historia de un pintor israelí que estaba en huelga de hambre debido a que la ley no le permitía casarse con su novia por tener una religión diferente. ${ }^{104}$ Il Calendario del Popolo, por su parte, tachaba al MAPAI -principal partido israelí- de "socialde-

99 L'Unità: 'L'Unione Sovietica ha rotto i rapporti diplomatici con Israele', 13 febrero 1953, p.6

100 L'Unità: 'Chi è l'aggressore?', 8 noviembre 1955

101 PESCETTI, Paolo: 'Le carte sporche dell'imperialismo nella vertenza tra Egitto e Israele', L'Unità, 12 noviembre 1955 , p.3

102 Ibidem.

103 Il Calendario del Popolo: 'La Repubblica di Israele', diciembre 1955, p.2187

104 L'Unità: 'Digiuna per amore un pittore israeliano', 16 marzo 1955, p.6 
mócrata de derechas". ${ }^{105}$ Israel era ahora descrito, ya no como un campeón de la lucha antiimperialista, sino como "un peón de la política americana". ${ }^{106}$

L'Unità aumentó sus ataques contra Israel en 1956, año en el que la URSS condenó la invasión de Egipto por parte de las tropas anglo-franco-israelíes. Las "principales características" del Estado hebraico eran ahora "el activismo militar, el expansionismo y la psicosis antiárabe". ${ }^{107}$ El diario del PCI no se conformó con criticar la política exterior israelí con respecto a la crisis con Egipto, sino que reinscribió toda la historia del conflicto árabe-israelí. Se sentenció que el territorio israelí "jamás había sido invadido por los árabes" y se llegó a insinuar que "los dirigentes de Israel habían aplicado a los árabes las mismas medidas de persecución que los judíos habían padecido en la Alemania de Hitler". ${ }^{108}$ En otro artículo se podía leer un comentario que, incluso, parecía cuestionar el derecho a existir de Israel:

Los árabes, con razón, jamás habían aceptado que se pudiera dar una patria a un millón y medio de judíos echando de sus casas y de sus tierras a un igual número de árabes ${ }^{109}$

Además, ya no eran las estructuras feudales árabes las que le tenían miedo al democrático y moderno Israel, sino que era el reaccionario Estado hebraico que se sentía amenazado por la fuerza emancipadora de sus vecinos:

Los israelíes han visto en el gran movimiento de emancipación de los pueblos árabes no un peligro por su seguridad de nación pacífica, sino una amenaza para sus designios de expansión industrial y hegemonía económica. ${ }^{110}$

Los enemigos de Israel se comenzaron a presentar como los nuevos héroes de la región. A medida que se desmontaban los argumentos relativos al maravilloso jardín que los israelíes habían construido en Palestina, se construían nuevos discursos sobre las prodigiosas hazañas de los nuevos paladines del antiimperialismo. L'Unità comparaba la presa de Asuán construida por el régimen de Gamal Abdel Nasser con las pirámides de los faraones. ${ }^{111}$

En 1957, después de una larga campaña denigratoria, L'Unità parecía convencida de que ya había borrado de la memoria de sus lectores la época en la que ensalzaba a los pioneros judíos:

\footnotetext{
105 Il Calendario del Popolo: 'La Repubblica di Israele'...

106 HANDLER, John: 'Il primo ministro di Israele dichiara di essere disposto ad incontrarsi con Nasser', L'Unità, 3 noviembre 1955, p.7

107 JACOVIELLO Alberto: 'Viaggio nel mondo arabo', L'Unità, 27 abril 1957, p.3

108 Ibidem.

109 JACOVIELLO, Alberto: 'L'opinione degli arabi su Israele', L'Unità, 26 septiembre 1957, p.3

110 JACOVIELLO Alberto: 'L'opinione degli arabi...'

111 PESCETTI, Paolo: 'La politica economica di Bandung ha aperto all'Egitto il mercato socialista', L'Unità, 14 marzo 1956, p.3
} 
Dicen tonterías quienes afirman que el 'milagro de Israel' se debe a la peculiar capacidad de sus habitantes frente a una pretendida incapacidad orgánica de los árabes para hacer lo mismo. ${ }^{112}$

\section{Una tierra, dos pueblos, múltiples representaciones}

Cabe destacar que dos de los seis periódicos analizados por el presente trabajo continuaron construyendo la leyenda rosa también después de 1949, lo que pone inequívocamente de manifiesto que lo que cambió no fue la realidad material de Israel, sino su representación cultural. En junio de 1950 Il Libertario, un órgano de prensa radicalmente anti-bolchevique, tachó de "idioteces" y de "estúpidas leyendas" los artículos de L'Unità que describían los Kibutz como lugares de explotación capitalista. ${ }^{113}$ Il Ponte, periódico independiente del PSI, todavía en diciembre de 1956, tras el fin de la guerra del Sinaí, describía a Israel y a Egipto de la siguiente forma:

Por un lado tenemos a un régimen en el que vive medio millón de árabes como minoría nacional respetada, con sus representantes parlamentarios, con sus escuelas y cooperativas, en armonía con un millón y medio de judíos; un régimen en el que no existe analfabetismo (...) en el que se garantiza igualdad social (...). Al otro lado (...) un régimen militar y dictatorial, en el que no existe parlamento, donde la 'inspiración' coránica por la 'guerra santa' se completa con la filosofía de la revolución inspirada en el Mein Kampf y en los delirios sobre los 'derechos de las naciones proletarias' 114

Todavía más significativo es el caso del Avanti!, que -tras haber cambiado su línea editorial a finales de 1949, pasando de la idealización a la demonización de Israelvolvió a suavizar sus críticas contra el Estado hebraico durante la crisis de Suez de 1956, justo cuando se deterioraban las relaciones entre PCI y PSI. Después de la guerra, los dos partidos se habían unido en el Frente Democrático Popular, en un momento en el que el PSI también manifestaba una radical tendencia filosoviética. Sin embargo, el PSI se alejó paulatinamente de las posiciones de Moscú, y consecuentemente del PCI. Una grave ruptura se produjo tras conocerse el contenido del discurso de denuncia del estalinismo que Nikita Kruschev pronunció en 1956 en ocasión del XX Congreso del Partido Comunista Soviético, rompiéndose definitivamente en octubre del mismo año debido a la revolución antisoviética que se produjo en Hungría. Durante la crisis de Suez, que se desarrolló en los mismos días que los sucesos de Budapest, el diario socialista fue así protagonista de un nuevo clamoroso viraje. Tras condenar la agresión contra Egipto por parte de las tropas de Londres y París, el diario aclaró que la actitud de Israel -que también había atacado al régimen de Nasser- era menos fácil de juzgar.

112 JACOVIELLO Alberto: 'L'opinione degli arabi...'

113 VELLA, Giuseppe: 'I “Kibbutz” palestinesi', Il Libertario, 21 junio 1950

114 LEVI, Leo: 'Sinai e Suez, democrazia e neonazismo, paradossi di allora e di oggi', Il Ponte, diciembre 1956, p.2073 
El pueblo israelí se ha merecido la comprensión general por la situación de cerco en la que ha acabado en Oriente Medio, y finalmente por lo que ha logrado crear en la tierra de Palestina. ${ }^{115}$

\section{Conclusiones}

A la luz de lo que ha sido expuesto anteriormente, podemos afirmar que, a caballo entre los años 40 y 50, los periódicos comunistas, socialistas y anarquistas construyeron y desmontaron reiteradamente la identidad de israelíes y palestinos, fabricando un gran número de heterogéneas representaciones del conflicto de Oriente Medio. Dichas representaciones no tenían nada que ver con la realidad de Palestina, sino que obedecían a cuestiones políticas e ideológicas del todo ajenas a lo que ocurría en Tierra Santa. A este propósito es oportuno reiterar que estas descripciones de la patria judía tuvieron lugar en un momento histórico en el que en Israel no se estaban produciendo grandes cambios políticos, manteniéndose en el poder los laboristas del MAPAI durante todo el periodo analizado.

Es preciso además desmentir aquellas teorías según las cuales la benévola actitud hacia Israel se debía a la empatía que la izquierda experimentaba debido a las persecuciones padecidas por los judíos. En realidad, el recuerdo del holocausto no fue ningún obstáculo a la hora de llevar a cabo políticas anti-israelíes. El Avanti! atacaba Israel en 1949, cuando la memoria de las matanzas hitlerianas estaba todavía muy viva, suavizando en cambio su ofensiva en 1956. Del mismo modo, el apoyo de L'Unità a Israel fue más fuerte en 1947 que en 1945. Tampoco fue determinante el peso de las relaciones que muchos líderes árabes habían tenido con los nazis. ${ }^{116} \mathrm{De}$ hecho, ya en 1949 la prensa de PCI y PSI mantenía una política filo-árabe.

Asimismo, los cambios en la representación de Israel tampoco tuvieron relación con la llegada al poder de movimientos islámicos antiimperialistas. Si la campaña anti-israelí comenzó a finales de 1949, todavía en febrero de 1955 la prensa comunista tachaba a Nasser de "fascista e imperialista" ${ }^{117}$ Lo cierto es que, tras alejarse de Israel, los países comunistas tardaron unos años en entablar relaciones amistosas con el régimen egipcio.

Del mismo modo, las purgas antijudías llevadas a cabo en la URSS no impidieron que la prensa comunista defendiese al mismo tiempo la causa sionista en Palestina. En efecto, la fase más filo-israelí de la prensa italiana de izquierdas (1947-1949) coincidió con una temporada de duras campañas anti-hebraicas en Rusia. El escritor Elie Wiesel recordó que desde 1948 a 1952 los judíos rusos vivieron unos "años negros". ${ }^{118}$

Lo cierto es que las campañas de elogio y descrédito de Israel dependieron más bien de la evolución de las dinámicas de la guerra fría. Como ha señalado Luca Riccardi, el cambio de actitud del PCI hacia Israel se debió principalmente "a la evolución, no

\footnotetext{
115 Avanti!: 'Aperta aggressione', 31 octubre 1956

116 CULLA, Joan B.: La tierra más disputada ..., p.128

117 Rinascita: 'Un primo bilancio del regime di Nasser', febrero 1955, pp.101-107

118 WIESEL, Elie: Los judios del silencio, Buenos Aires, Paidós, 1968, p.127
} 
siempre coherente, de la política medioriental de la URSS". ${ }^{119}$ No es de extrañar que los órganos de prensa ligados al PCI defendieran a Israel cuando éste era respaldado por los soviéticos, criticándolo ferozmente cuando Moscú cambió radicalmente su política exterior con respecto a Oriente Medio. Tampoco fue casualidad que en 1953 disminuyesen los artículos contra el Estado hebraico publicados por la prensa comunista, pues tras la muerte de Stalin la Unión Soviética normalizó sus relaciones con Israel, poniendo fin además a las campañas anti-semitas de la época estaliniana. Con todo, pocos meses más tarde, las relaciones entre Unión Soviética e Israel volvieron a deteriorarse, lo que trajo consigo la reaparición, en la prensa comunista, de cada vez más frecuentes artículos contra Israel. En suma, tal y como denunciaba en 1952 el intelectual y político antifascista Ernesto Rossi, la prensa comunista y filocomunista mostraba "demasiado la trama de las intenciones de Moscú" y estaba demasiado desacreditada por la facilidad con la cual mezclaba continuamente "la verdad con la mentira". ${ }^{120}$

Resulta del todo evidente que, para la prensa de izquierdas de la época, el conflicto de Oriente Medio fue sobre todo una excusa para llevar a cabo campañas mediáticas en contra de los países capitalistas. No podemos olvidar que tanto Israel como los países árabes lucharon en aquellos años por su emancipación de las potencias coloniales. ${ }^{121}$ A todo eso hay que añadir que Oriente Medio también se convirtió en uno de los escenarios de la guerra fría. ${ }^{122}$ Inicialmente Moscú y Washington estuvieron de acuerdo con dar luz verde al proyecto de partición de Palestina, sin embargo con el tiempo ambas naciones comenzaron a temer que la potencia enemiga intentaría suplantar a Francia e Inglaterra como nueva fuerza hegemónica en Oriente Medio. ${ }^{123}$ De ahí que los israelíes fueran descritos como las víctimas de ingleses y norteamericanos, mientras que sus vecinos eran presentados como la herramienta que los imperialistas utilizaban para mantener el control de la región. Esto, por lo menos, hasta que los papeles no fueron arbitrariamente invertidos, con los palestinos repentinamente transformados en mártires, y los judíos en los títeres de las despiadadas multinacionales occidentales.

De la misma forma, fundamentales fueron las turbulentas relaciones entre los partidos de izquierdas en el ámbito del juego político italiano. El comunismo transalpino mantuvo siempre una clara actitud filo-soviética, una postura que no vaciló ni siquiera después del discurso secreto de Kruschev y de la invasión de Hungría del ejército rojo. Los anarquistas, por el contrario, se declararon siempre en contra del totalitarismo ruso. Los socialistas, por su parte, se dividieron. El PSI mantuvo al principio una postura radicalmente filo-soviética, distanciándose de las posiciones de Moscú en 1956, año en el que se produjo la ruptura con el PCI. Los socialistas moderados, por su parte, desconfiaron siempre de la dictadura rusa. Lo cierto es que si la dependencia de Moscú de PCI y PSI provocó el nacimiento, a finales de 1949,

119 RICCARDI, Luca: Il problema Israele ..., p.10

120 Citado en MURIALDI, Paolo: 'La stampa italiana del dopoguerra'...

121 CULLA, Joan B.: La tierra más disputada ..., p.143

122 MAYER, Arno J.: El arado y la espada : del sionismo al estado de Israel, Barcelona, Península, 2010, pp.348-349

123 PAPPÉ, Ilan: Historia de la Palestina moderna : un territorio, dos pueblos, Madrid, Akal, 2007, p.177 
de una leyenda negra en contra de Israel, la actitud antibolchevique de anarquistas y socialistas moderados hizo que Il Libertario e Il Ponte perpetuaran y reforzaran la leyenda rosa. Asimismo, la definitiva ruptura de las relaciones entre PSI y PCI hizo que el Avanti! abandonara en 1956 su guerra mediática contra Israel. Cabe además señalar que la izquierda italiana siempre tuvo la tentación de defender a Israel debido a que el Vaticano mantenía una cierta hostilidad con respecto al Estado hebraico. Durante los primeros años de existencia de Israel, además, las relaciones bilaterales entre los gobiernos israelíes y los ejecutivos democristianos de Roma (adversarios políticos de la izquierda) fueron bastante frías, y eso pese a los continuos intentos, por parte de Israel, de mejorar la situación diplomática entre los dos países. ${ }^{124}$

La fabricación de la imagen de israelíes y palestinos, en ambas versiones -la buena y la mala- se llevó a cabo, o bien ocultando o bien destacando de forma exagerada algunos hechos particulares, siempre en beneficio de la tesis que se pretendía presentar a los lectores. Lo verdaderamente importante era la narración, no los hechos, estando los acontecimientos subordinados a los discursos. Incluso las cifras, como por ejemplo aquéllas relacionadas con los datos demográficos, fueron interpretadas de forma muy diferente, tanto para justificar la existencia del Estado de Israel como para poner en duda la legitimidad de la presencia de un hogar judío en la región.

Los estereotipos presentes en estas representaciones eran muy a menudo los mismos, y las historias que se relataban tenían siempre la misma estructura: por una parte un colectivo agresor, fundamentalista, al servicio de los imperialistas; por otra un colectivo explotado pero no resignado, víctima de atroces abusos pero dispuesto a luchar por la libertad. Hasta 1949 los palestinos fueron enmarcados dentro del primer grupo y los israelíes dentro del segundo. Posteriormente se siguió contando prácticamente la misma historia, sólo que los roles de palestinos y judíos fueron repentinamente invertidos.

También es significativo el hecho de que, en estas reconstrucciones, tanto los israelíes como los palestinos eran constantemente privados de su individualidad, siendo representados como colectivos unitarios, sin matices, enteramente buenos o malos, violentos o pacíficos, portadores, o bien de civilización, o bien de barbarie. Se ignoraba deliberadamente la enorme complejidad del conflicto, produciéndose narraciones que presentaban esquemas increíblemente sencillos, los cuales presentaban una dinámica de lucha permanente entre opresores y oprimidos. Cabe además señalar que el término "palestino" se empleaba para indicar a los israelíes, mientras que el término "árabe" acababa enmarcando a todas las poblaciones no-judías de Oriente Medio.

La imagen que los lectores italianos de la época acabaron teniendo sobre israelíes y palestinos no estaba relacionada con los actos llevados a cabo por los individuos que formaban parte de estos colectivos, dependiendo por el contrario de las verdades producidas por los escritos propagandísticos de los periodistas de estos órganos de prensa, los cuales construian y deshacian al israelí y al palestino en los que sus lectores tenían que creer. Lo que palestinos y judíos hacían, querían y sentían dependía de la voluntad política, la destreza y la imaginación de los guionistas que escribían, a varios miles de kilómetros de distancia, las epopeyas de sus hazañas o las miserias

124 RICCARDI, Luca: Il problema Israele.., p.9 y 36-38 
de sus infamias. Se trataba, en suma, de falsas verdades: falsas porque no estaban relacionadas con lo que realmente estaba ocurriendo en Oriente Medio, pero aun así verdades, porque lograban imponerse, a los ojos de los receptores de estos mensajes, como lo que efectivamente estaba desarrollándose en Palestina. No eran nada más que ilusiones generadas por el lenguaje, y sin embargo para los lectores de estos periódicos estas narraciones eran el puente que los ponía en contacto con la Palestina de su tiempo.

Considerando que la realidad de israelíes y palestinos ha sido construida y desmontada una y otra vez debido a intereses políticos nacionales y a las dinámicas de la guerra fría, cabe preguntarse qué consecuencias produjeron a largo plazo estas representaciones. Resulta evidente que para estos periódicos los hechos tenían una importancia muy relativa, y que su objetivo no era el de informar sobre los acontecimientos que ocurrían en Oriente Medio, sino el de convencer a sus lectores de que Israel era amigo -o enemigo- de la causa por la que estos órganos de prensa estaban luchando. Pero ¿sabían estos lectores que se trataba de mera propaganda, o por el contrario las representaciones de estos periódicos modificaron su forma de pensar sobre el conflicto árabe-israelí? ¿En qué medida los estereotipos construidos en países occidentales como Italia fueron utilizados por los nacionalismos de Oriente Medio? ¿En qué medida estas construcciones culturales favorecieron el odio entre palestinos y judíos, obstaculizando el proceso de paz? ¿En qué medida los falsos mitos que fueron construidos entonces siguen presentes hoy día en los discursos de altos dirigentes y personas ordinarias? En suma, futuros trabajos deberían tener como objetivo el estudio -en palabras de Edward W. Said- de la transición desde una definición meramente textual de estas representaciones hasta su puesta en práctica. ${ }^{125}$

\section{Referencias bibliográficas}

BEN AMI, Shlomo y MEDIN, Tzvi: Historia del Estado de Israel : (génesis, problemas y realizaciones), Madrid, Rialp D.L., 1992

BIALER, Uri: Between East and West: Israel's foreign policy orientation 1948-1956, Cambridge, Cambridge University Press, 1990

BURKE, Peter: La Fabricación de Luis XIV, Madrid, Nerea, 1995

CULLA, Joan B.: La tierra más disputada : el sionismo, Israel y el conflicto de Palestina, Madrid, Alianza, 2005

DI FIGLIA, Matteo: Israele e la sinistra : gli ebrei nel dibattito pubblico italiano dal 1945 a oggi, Roma, Donzelli, 2012

ISRAEL GARZÓN, Jacobo: El exilio republicano español y los judios : apuntes de literatura, Madrid, Hebraica, 2009

MAYER, Arno J.: El arado y la espada : del sionismo al estado de Israel, Barcelona, Península, 2010

MENDES, Philip: "The Australian Left's Support for the Creation of the State of Israel, 1947-48", Labour History, No. 97 (Nov., 2009), pp. 137-148

125 SAID, Edward W.: Orientalismo, Barcelona: Debolsillo, 2009, p.139 
MURIALDI, Paolo: La stampa italiana del dopoguerra : dalla liberazione agli anni del centrismo, Roma-Bari, Laterza, 1978

PAPPÉ, Ilan: La Limpieza étnica de Palestina, Barcelona, Crítica, 2008

PAPPÉ, Ilan: Historia de la Palestina moderna: un territorio, dos pueblos, Madrid, Akal, 2007

RADOSH, Ronald y RADOSH, Allis: "Righteous among the editors : when the Left Loved Israel”, World Affairs, Verano 2008, pp.65-75. DOI: 10.3200/ WAFS.171.1.65-75

RICCARDI, Luca: Il problema Israele : diplomazia italiana e PCI di fronte allo Stato ebraico, 1948-1973, Milano, Guerini studio, 2006

SABORIDO, Mercedes: "De "defensores de una causa santa" a "lacayos del imperialismo". El Partido Comunista de la Argentina y el conflicto de Suez (1956)", Cuadernos de Historia Contemporánea, 2013, vol. 35, pp.193-218. http://dx.doi. org/10.5209/rev_CHCO.2013.v35.42655

SAID, Edward W.: Orientalismo, Barcelona, Debolsillo, 2009

TAGUIEFF, Pierre-André: La Nueva judeofobia, Barcelona, Gedisa, 2003

WIESEL, Elie: Los judios del silencio, Buenos Aires, Paidós, 1968. 